\title{
REVIEW \\ The peppered moth and industrial melanism: evolution of a natural selection case study
}

\author{
LM Cook ${ }^{1}$ and IJ Saccheri ${ }^{2}$
}

From the outset multiple causes have been suggested for changes in melanic gene frequency in the peppered moth Biston betularia and other industrial melanic moths. These have included higher intrinsic fitness of melanic forms and selective predation for camouflage. The possible existence and origin of heterozygote advantage has been debated. From the 1950s, as a result of experimental evidence, selective predation became the favoured explanation and is undoubtedly the major factor driving the frequency change. However, modelling and monitoring of declining melanic frequencies since the 1970 s indicate either that migration rates are much higher than existing direct estimates suggested or else, or in addition, non-visual selection has a role. Recent molecular work on genetics has revealed that the melanic (carbonaria) allele had a single origin in Britain, and that the locus is orthologous to a major wing patterning locus in Heliconius butterflies. New methods of analysis should supply further information on the melanic system and on migration that will complete our understanding of this important example of rapid evolution.

Heredity (2013) 110, 207-212; doi:10.1038/hdy.2012.92; published online 5 December 2012

Keywords: Biston betularia; carbonaria gene; mutation; predation; non-visual selection; migration

\section{INTRODUCTION}

The peppered moth Biston betularia (L.) and its melanic mutant will be familiar to readers of Heredity as an example of rapid evolutionary change brought about by natural selection in a changing environment, even if the details of the story are not. In fact, the details are less simple than usually presented; they have accrued and undergone changes in emphasis during the century and a half of study. In this review, we outline the way patterns, techniques and ideas have evolved and discuss the problems that remain to be solved. (Industrial melanism in Biston betularia (L.) involves complex historical and geographical changes in habitat and ecology (Kettlewell, 1973; Berry, 1990; Majerus, 1998). The original phenotype was speckled black and white (typical). Melanic forms are the almost uniform black carbonaria and several intermediate phenotypes (insularia). In the north English industrial region, insularia alleles played little part in change of melanic frequency, but in south Wales and adjacent parts of England, they reached high frequencies and had a different history. Similarly, industrialisation developed in different ways in different places. For hundreds of years until the eighteenth century, London was the most industrialised and polluted city. After that, industry developed, and sometimes declined at an early date, in places we now think of as rural. In areas that remained industrial, the extent of continuous conurbation varied considerably. Atmospheric pollution, darkening of surfaces, food plant abundance and predators therefore also vary. To keep the description simple, just two pairs of categories have been used where possible in this account: melanic and typical moths, and industrial and rural habitats. For the same reason, parameter estimates are given to the nearest order of magnitude, although original calculations are more precise and more qualified. There is no attempt to review the full contributions of the various authors cited.)

\section{EARLY EVIDENCE OF CHANGE}

The peppered moth was the most diagrammatic example of the phenomenon of industrial melanism that came to be recognised in industrial and smoke-blackened parts of England in the mid-nineteenth century. The typical individual has a sprinkling of black marks on a white background. Melanic forms (almost uniform black carbonaria and intermediate insularia) were shown to be determined by a series of dominant alleles at a single locus (Bowater, 1914 and many later studies. The early controversy involving induction of melanic variants is reviewed by Rudge, 2009). They, and melanic variants in numerous other moth species, increased in frequency during the nineteenth century. In the peppered moth, the increase was so great that in some industrial parts of England the original wild type was almost lost by the end of the century. Records were made by amateur lepidopterists and discussed in the entomological literature, particularly as regards why melanic forms arise in nature (Rudge, 2010). Tutt (1891, later published separately) considered the possible factors implicated-humidity, environment, heredity, disease, temperature or protection (meaning camouflage)—without clearly favouring a single cause; he credits the idea of protection and natural selection to White (1877) and Chapman (1888). Shortly after, he used the peppered moth as the example in a vivid description of selection for crypsis by predators in a changing environment (Tutt, 1894), later repeated even more emphatically (Tutt, 1896; see Owen, 1997). There were no records of predation at the time, and other writers such as Prest (1877) and, in an important review, Porritt (1907) disagreed. At the instigation of Bateson (1900), who wished to assemble examples of discontinuous variation, the records were brought together (Barrett, 1901; Doncaster, 1906) to provide a starting point for wider discussion.

${ }^{1}$ Faculty of Life Sciences, School of Life Sciences, University of Manchester, Manchester, UK and ${ }^{2}$ Institute of Integrative Biology, University of Liverpool, Liverpool, UK Correspondence: Dr LM Cook, Faculty of Life Sciences, School of Life Sciences, University of Manchester, Oxford Road, Manchester M13 9PT, UK. E-mail: Icook@manchester.ac.uk

Received 9 August 2012; revised 1 October 2012; accepted 15 October 2012; published online 5 December 2012 
Punnett (1915) summarised the view that birds did not act as selective agents. He also pointed out that the increase in melanic peppered moths implied appreciable selection, noting breeding results that suggested melanics were hardier. Haldane (1924) estimated the average selection required, which was much greater than the level hitherto associated with evolutionary change. Since then, strong selection has been an accepted part of the peppered moth story. Just how strong is more difficult to settle, as the change was from one extreme frequency to the other, but one of Haldane's calculations suggested an advantage as great as 30 per cent.

The phenomenon of industrial melanism was discussed by Ford (1937, 1953, 1955) in relation to the prevalence of polymorphism. Ford defined polymorphism as 'the occurrence together in the same locality of two or more discontinuous forms of a species in such proportions that the rarest of them cannot be maintained merely by recurrent mutation' (Ford, 1964). The unstated assumptions were that mutations are deleterious and selection rules out drift. Current definitions include drift and allelic, as distinct from phenotypic, variability, so that allelic polymorphism is coexistence with the most common allele at no more than 99 per cent. Ford distinguished stable from transient polymorphisms, the best example of the latter being the peppered moth. Why were the melanic mutants dominant and advantageous when most mutants are deleterious and recessive? Ford offered some possible answers.

\section{FORD'S ECOLOGICAL GENETICS}

There are over 200 species of British moths with naturally occurring melanic variants (Bowater, 1914). Ford had a wide knowledge of them and combined with it ideas about the nature of dominance. These were developed by Wright (1929), Haldane (1930) and others, but came to him particularly from Fisher $(1928,1930,1931)$. Other things being equal, a newly arisen mutant heterozygote would be disadvantageous and distinguishable from the wild-type homozygote, but repeated selection against it would favour individuals with genotypes in which the mutant phenotype was poorly expressed. The genome becomes adjusted to the normal requirements of the organism. Ford considered the case of an advantageous mutant. Increasing dominance would enhance its fitness. If it was pleiotropic, advantageous traits would tend to dominance and disadvantageous ones to recessiveness. Heterozygote advantage (HA) would develop, and we should expect that many of the observed polymorphisms resulted from HA. This is the ostinato that runs through Ecological Genetics (Ford, 1964), and has had repeated echoes with respect to interpretation of changes in the peppered moth.

Moth species often have melanic variants at low frequency outside of industrial regions. They may have been favoured in the forests that formerly clothed much of northern Europe, in the course of time becoming visually dominant and fittest as heterozygotes. That would explain both their occurrence in rural parts and their sudden rise in frequency when again favoured by changes consequent on industrialisation (Ford, 1937, 1955).

This speculation received a boost when Haldane (1956) noted that in Manchester the peppered moth reached a high melanic frequency but not complete fixation. Perhaps, (1) selection was less intense than previously calculated, (2) immigrants came from unpolluted areas (both considered unlikely) or (3) there was HA. Kettlewell (1958) and Sheppard favoured the last option (Clarke and Sheppard, 1963). Sheppard worked closely with Ford at Oxford. Later, in Liverpool, he collaborated with Clarke to analyse mimetic polymorphisms in swallowtail butterflies (for example, Sheppard, 1959). These were not maintained by HA, but illustrated the development of supergenes consisting of loci operating together to perfect the phenotype. Sheppard also studied peppered moths, identifying a cline of melanic morph frequency running from Liverpool into north Wales (Clarke and Sheppard, 1966). At the industrial end of this transect, data from three successive dates were fitted better if HA were assumed than if it were not.

\section{KETTLEWELL'S SURVEYS AND EXPERIMENTS}

That was the intellectual environment in which Kettlewell began work on melanism in Lepidoptera in general and the peppered moth in particular (Kettlewell, 1956, 1973). He had a formidable knowledge of Lepidoptera (Berry, 1990) and made his own independent research plans (Rudge, 2006, 2010), but many of his experiments and observations echo Ford's theoretical preoccupations. He located early melanic specimens in museums and considered whether expression had evolved. He looked for dominance breakdown in crosses of individuals from widely separated places. Some of his work involved species with polymorphisms in Scottish pine forests and northern isles (Kettlewell, 1961; Kettlewell and Berry, 1961; Kettlewell and Cadbury, 1963), where local habitats might shed light on the origin of dominant melanics. He was content with the assumption of HA (Kettlewell, 1958). But above all, he took the peppered moth studies forward in two important ways. He coordinated country-wide surveys of morph frequency (1958 and 1965), which became the standard to compare earlier and later work, and produced the first convincing evidence that birds eat the moths and could do so selectively (Kettlewell, 1955). Following his example, other authors tested for selective predation with moths of different phenotypes exposed on trees to be eaten (Clarke and Sheppard, 1966; Bishop, 1972; Lees and Creed, 1975; Whittle et al., 1976; Steward, 1977a; Bishop et al., 1978; Murray et al., 1980; Howlett and Majerus, 1987). Overall, these experiments suggested that the melanic peppered moth had an advantage of up to 2 to 1 over the typical form in industrial locations, where melanic frequency was 80 per cent or more, but a disadvantage, sometimes large, where the frequency was lower. In SW England, where melanics were almost absent, Kettlewell's result suggested a fitness difference of the order of 1 to 2 .

As Kettlewell was making a quantitative study of melanism in the peppered moth, Ford's ecological genetics programme began to come apart. Instead of being commonplace, very few cases of HA were actually made to stick (Lewontin, 1974). Researchers took to studying enzymes and base sequences rather than distinct phenotypes. The neutral model of evolution was an increasingly attractive way to interpret them (Kimura, 1983), and the idea of evolution of dominance through modifiers was criticised (for example, Charlesworth, 1979).

\section{BALANCE OF VISUAL SELECTION AND MIGRATION}

The industrial environment was also radically altered. In the 1970s, old grimy building stock was removed, and smoke control introduced. Observations from Liverpool and north Wales were extended eastwards to Manchester and, using data of Sutton, as far as Leeds in Yorkshire, to produce a well-defined transect on which changes could be monitored (Bishop et al., 1978). The first slight indication of increase of typicals in smoky locations was noted (Askew et al., 1970; Lees and Creed, 1975). Transects were compared in south Wales, Birmingham and adjacent more rural regions (Lees, 1981).

It was always clear that migration might influence frequency changes, but little information existed (Kettlewell, 1958). Early dispersion of melanic forms, as they spread progressively southward, suggested that migration rates could be high (Steward, 1977b). Bishop 
(1972) was the first to provide an estimate. Using marked adults released at a central point and recaptured in traps progressively distant from it, he showed that male moths could move an average of about $2 \mathrm{~km}$ per night. The small amount of information available suggests an effective density of 40-50 moths per $\mathrm{km}^{2}$ (Bishop, 1972; Saccheri et al., 2008).

With these results it became possible to examine the basic tenets of the Ford model. Using estimates of visual selection along it, Bishop fitted a curve to the frequency cline in north Wales. There were too many melanics to the west, which could indicate that heterozygotes had a non-visual selective advantage (agreeing with the suggestions of Haldane and Sheppard). Must it therefore be assumed that HA had developed, or had always been present, in this system? Sheppard considered that it was (Whittle et al., 1976) supported to some extent by Bishop, but perhaps the country-wide pattern could be reproduced assuming directional selection and migration alone (Bishop and Cook, 1975; Bishop et al., 1978). Modelling was attempted with selection values based on the predation experiments, and migration rate and density based on Bishop's estimates (Cook and Mani, 1980). This showed that if selection estimates were about right, migration had to be some 10 times greater than assumed. If not, melanics must have a non-visual advantage. There was, however, no evidence that HA would help.

\section{NON-VISUAL SELECTION}

From their experiments on predation and conspicuousness, Lees and Creed (1975) concluded that other factors besides predation influenced melanic frequency. Creed et al. (1980) examined all available breeding records in which melanics and typicals segregated83 crosses and over 12000 progeny. Although not formally significant, the results suggested that survival to adult was higher for homozygous melanics than for other genotypes. Mani (1980) reanalysed the north Wales cline and found he could best describe it if he accepted the advantage indicated by this analysis. Weak frequency-dependent protection of rare morphs is also possible (Whittle et al., 1976; Bishop and Cook, 1980). Using this assumption, too, Mani produced further theoretical analyses and satisfactory fits to field records (Mani, 1982, 1990; Mani and Majerus, 1993; Cook et al., 1998).

In some insects, diet affects availability of melanin precursors, which in turn influences coloration (Talloen et al., 2004). Their synthesis is involved not only in melanin production but also immune defence and sclerotin production, so that competitive trade-offs are possible (Windig, 1999; Stoehr, 2006). Pre-adult fitness differences between melanic and non-melanic morphs are reported for the noctuid species Mythimna separata (Jiang et al., 2007). In some moths and other insects, individuals with darker cuticles tend also to have stronger immune defence (True, 2003; Mikkola and Rantala, 2010) and immune defence and wing melanization can interact (Freitak et al., 2005). Immune encapsulation of foreign bodies can be triggered by heavy metal pollution (van Ooik et al., 2008). None of these investigations involve peppered moths, but they are evidence that change in visible melanic phenotype may be accompanied by other adjustments.

\section{MOTH SETTLING POSITION}

Another variable about which too little was known was the pattern and strength of visual selection. In Kettlewell's experiments, melanic and typical moths were at relatively high densities. There was a massive difference in relative visibility of the forms to the human eye between industrial and rural locations, and a corresponding difference in selective removal by birds. Experiments by others gave comparable results. But what matters is avian rather than human vision. To improve the estimates, it is critical to know how birds react to moths settled at the density and in the locations they adopt under their own volition. These aspects were investigated by Mikkola (1979, 1984), Howlett and Majerus (1987) and Liebert and Brakefield (1987). Although some rest on trunks (36 per cent; Majerus, 2007; Cook et al., 2012), most moths are higher in trees under horizontal branches or in the crooks of smaller branches, where they are better protected from predation (Mikkola, 1979). Howlett and Majerus (1987) compared individuals in the two types of resting position and found the disadvantage of melanics was halved by being in the better place. Under UV, which is visible to birds, carbonaria individuals are inconspicuous on foliose lichens, which may give them added protection in rural regions (Majerus et al., 2000). These may be reasons why Bishop failed to predict the spread of melanics into north Wales (Majerus, 1998).

The actual selective values remained uncertain. Moths are more abundant in rural than industrial regions, which have fewer suitable trees, more disorienting lights and different associations of birds. Industry and climate also affect epiphyte cover on many of the surfaces where moths can settle, suggesting possible interaction with changes in another biotic system (Lees et al., 1973; Lees, 1981; Howlett and Majerus, 1987; Cook et al., 1990). Direct and indirect approaches can be used to learn more about these factors.

\section{FURTHER ESTIMATES OF SELECTION}

Majerus (2007) adopted the direct approach in a properly controlled experiment. Over 6 years he allowed a total of 4864 moths at the melanic frequency for the location to settle naturally at low density in a wooded area near Cambridge. The results, including direct observation of predation, showed that birds exerted a selective pressure of about 10 per cent against melanics compared with typicals (Majerus, 2007; Cook et al., 2012). The actual selection may be larger depending on the length of life of the moths and the extent of continuing selective predation. The melanic frequency in the population from which the experimental animals came was also declining. Taken together, the data on changing frequency in Cambridge (Lees and Creed, 1975; Majerus, 1998, Cook and Turner, 2008) suggest a disadvantage of the same order.

Similar selective values emerged from other surveys of changing frequency. An Open University survey in 1983/1984 showed the plateau of high frequency to have contracted compared with the picture produced by Kettlewell (Cook et al., 1986), consistent with an average melanic disadvantage of about 12 per cent. The Rothamsted Insect Survey from 1974 to 1999 indicated further contraction and an average disadvantage of about 10 per cent (Cook et al., 2002). Clarke and his co-workers (Clarke et al., 1985, 1990, 1994; Grant et al., 1996) sampled every year from 1959 to 2002 at a location near Liverpool. Series that are less complete, but better than any from the initial rise, are available for Leeds, York, Manchester, Nottingham, Cambridge and west Kent (listed in Cook and Turner, 2008). These provide figures from 8 to 35 per cent for different locations and periods. Of course, such estimates include a component due to migration, which will vary depending on how close the site is to a frequency cline.

Grant et al. (1998) made pairwise comparisons of early and late records separated by several generations, with comparable results. One interesting feature, noticeable because a wide range of locations was used, was that the rate of decline was lower where the initial frequency was lower (Cook, 2003). The estimated difference, with low migration and no non-visual advantage, is about 15 per cent selection against melanics in industrial areas, dropping to $2-3$ per cent in rural areas 
(Cook et al., 1990). An elementary interpretation, tenable if migration is low, is that selection is less intense in rural locations than in industrialised regions. This also accords with the experimental findings of Howlett and Majerus (1987).

Change in melanic frequency was not only a British phenomenon. Sequential records from the Netherlands (Brakefield and Liebert, 2000) and of the American subspecies in the United States (Grant et al., 1996; Grant and Wiseman, 2002) show that decline occurred in industrialised regions parallel to reduction in atmospheric pollution at rates comparable to those observed in Britain. These common correlations suggest a common cause.

\section{MIGRATION AGAIN}

The issue of migration is critical; change in morph frequency does not give a good measure of selection if there is high migration. Male adults move much further on the first than on subsequent nights (Brakefield and Liebert, 1990). Females tend to be sessile, but perhaps only if quickly discovered by a male (Cook, 2003). Newly emerged larvae also have a strong tendency to disperse, spinning threads that can carry them away from the oviposition site. Kettlewell noted that this spread them over a variety of food plants; it may reduce risk of predation, parasitisation and viral disease. If the larvae enter the air stream, however, they could go much further (Liebert and Brakefield, 1987), the distance depending on how high they get. Studies using radar tracking show that British noctuid moths can be displaced $400 \mathrm{~km}$ or more in $8 \mathrm{~h}$ by prevailing winds (Wood et al., 2009; Chapman et al., 2010).

In 2002 Saccheri collected a series of samples along the north Wales, north-west England cline to compare with the earlier records. The sensitive analytic procedure used by François Rousset (Saccheri et al., 2008) to relate the new pattern to the earlier cline suggests that migration is indeed much greater than hitherto assumed, implying that visual selection is strong along its full length and does not fall off to the west. A microsatellite-based isolation-by-distance estimate of gene flow along this cline was also consistent with high dispersal, but had a wide confidence interval (Saccheri et al., 2008).

\section{MOLECULAR ADVANCES}

In contrast to the analysis of morph frequency and predation data, molecular genetics have been applied to this system only recently. Informed by results from Drosophila (Wittkopp et al., 2003) and Papilio xuthus (Koch et al., 2000), it was initially thought likely that the developmental switch for melanism would be found within the canonical melanisation pathway (True, 2003). A survey of all the candidate genes revealed that this is not the case (Van't Hof and Saccheri, 2010), paving the way for a genome-wide segregation analysis of amplified fragment length polymorphisms, which localised the carbonaria locus to a chromosomal region with no known function in melanisation (Van't Hof et al., 2011). Curiously, and quite unexpectedly, the carbonaria region is orthologous to a major wing patterning locus controlling mimicry forms in Heliconius butterflies (Papa et al., 2008; Joron et al., 2011).

The specific identity and mode of action of the functional sequence polymorphism remains to be discovered. Progress in understanding the developmental mechanism may shed light on longstanding questions about pleiotropy (which could give rise to non-visual fitness effects) and what determines the degree of dominance of the various melanic morph alleles (the dominance rank of typical, insularia and carbonaria alleles follows the degree of melanisation). In this context, the availability of a linkage map encompassing all 31 chromosomes (Van't Hof et al., 2012), featuring melanisation and colour patterning genes, facilitates future genetic investigations.

Patterns of linkage disequilibrium around the melanism locus indicate that, throughout the United Kingdom, the melanic morph carbonaria is descended from a single mutational event in the recent past (Van't Hof et al., 2011), thus settling the question whether industrial melanism arose several times in Britain and showing that the initial extension of range was a result of migration. Ongoing work aims to document the genetic consequences of the rise and fall of carbonaria, principally by analysing changes in linkage disequilibrium and nucleotide diversity along the north Wales, north-west England cline through time, using archival material. These data will also provide an opportunity to detect any deviations in the expected frequencies of carbonaria homozygotes and heterozygotes.

\section{CONCLUSIONS}

The peppered moth remains the type example of rapid response to human-induced environmental change, driven by selective predation (Grant, 2012). Some of the issues with which it was once associated now receive less attention. Kettlewell's (1958) 'ancient carbonaria' remain to be properly examined at the genetic level, but there is evidence that modification of expression at the carbonaria locus may occur (see Grant (2004)). The question why melanic forms in so many species are dominant still needs an agreed answer. Dominance modification continues to be of interest in connection with the evolution of genetic systems (Mayo and Bürger, 1997; Bagheri, 2006). HA is not necessary to explain the changing gene frequency in the peppered moth, but there are other species where it could be important.

Breeding results suggest that homozygous melanic peppered moths may have a non-visual advantage, which, if true in the wild, would rule out HA. Creed et al. (1980) noted that the data are uncontrolled, and only part of the total data set is critical in establishing fitness difference. Further work is certainly needed, but if there really is a difference, melanics would have increased rapidly in polluted industrial regions with even a quite small visual advantage once sufficient melanic homozygotes had accumulated. At the end of the industrial period, there must correspondingly be strong visual disadvantage to overcome the non-visual fitness effect unless there is high migration. The following possibilities then exist to explain why rural areas continued to have low melanic frequencies:

\begin{tabular}{llll}
\hline $\begin{array}{l}\text { Option } \\
\text { Migration }\end{array}$ & $\begin{array}{l}\text { Melanic non-visual } \\
\text { advantage }\end{array}$ & $\begin{array}{l}\text { Melanic visual } \\
\text { disadvantage }\end{array}$ \\
\hline 1 & Moderate & None & Weak \\
2 & Moderate & Strong & Strong \\
3 & High & None & Strong \\
4 & High & Strong & Very strong \\
\hline
\end{tabular}

With an estimated displacement of about $2 \mathrm{~km}$ per day there could be a small visual disadvantage to melanics and little non-visual difference (option 1) or stronger visual selection coupled with substantial non-visual advantage (option 2). The analysis of decay of the north Wales cline suggests that migration is indeed greater by an order of magnitude than previously assumed, giving option 3 . If a non-visual advantage exists, then the visual disadvantage must have been even larger (option 4). At present, none of these options can certainly be eliminated. 
Migration and selection can be used interchangeably in models. It is therefore important to make better estimates of migration and to explore the question of non-visual fitness difference. As the melanics disappear, field studies on morph frequency change become increasingly difficult. With respect to migration, it would be possible to conduct further release and recapture trials. Tighter indirect estimates of gene flow, encompassing adult and larval stages, using a large panel of markers would also be useful. Adult females fly less than males. Comparison of the pattern of genetic isolation by distance for unlinked autosomal loci (for example, Daly et al., 2004) versus mitochondrial or $\mathrm{W}$-chromosome-linked loci could in principle detect dispersal differences between adult males and females.

A key outstanding question that has emerged from the recent molecular studies is the depth of phylogenetic conservation of the developmental regulator underlying the carbonaria mutant. We know that United Kingdom carbonaria is the result of a recent mutation event, but the existence of similar melanic phenotypes in other B. betularia populations (continental Europe and North America) and many other moth species suggests an ancestrally conserved mechanism. If this turns out to be true, it will be easier to explain the phenomenon of industrial melanism in moths, although not necessarily why such a 'hotspot' for melanism exists, given that insect melanism has several potential switches.

\section{CONFLICT OF INTEREST}

The authors declare no conflict of interest.

\section{ACKNOWLEDGEMENTS}

Many people have read and commented on earlier drafts of this paper. We are grateful to them all, with particular thanks to Bruce Grant and John Turner. We thank three anonymous referees whose observations have improved the presentation.

Askew RR, Bishop JA, Cook LM (1970). Increasing frequency of the typical form of the peppered moth in Manchester. Nat Lond 227: 1155.

Bagheri HC (2006). Unresolved boundaries of evolutionary theory and the question of how inheritance systems evolve: 75 years of debate on the evolution of dominance. $J$ Exp Zool Ser B 15: 329-359.

Barrett CG (1901). Lepidoptera of the British Isles. vol VII. Reeve: London.

Bateson W (1900). Collective enquiry as to progressive melanism in moths memorandum from the Evolution Committee of the Royal Society. Ent Rec 12: 140.

Berry RJ (1990). Industrial melanism and peppered moths. Biol J Linn Soc 39: 301-322.

Bishop JA (1972). An experimental study of the cline of industrial melanism in Biston betularia (L.) (Lepidoptera) between urban Liverpool and rural north Wales. J Anim Ecol 41: 209-243.

Bishop JA, Cook LM (1975). Moths, melanism and clean air. Sci Am 272: 90-99.

Bishop JA, Cook LM (1980). Industrial melanism and the urban environment. Adv Ecol Res 11: 373-404.

Bishop JA, Cook LM, Muggleton J (1976). Variation in some moths from the industrial north-west of England. Zool J Linn Soc 58: 273-296.

Bishop JA, Cook LM, Muggleton J (1978). The response of two species of moths to industrialization in northwest England. I. Polymorphisms for melanism. Philos Trans $R$ Soc Lond Ser B 281: 491-515.

Bowater W (1914). Heredity of melanism in Lepidoptera. J Genet 3: 299-315.

Brakefield PM, Liebert TG (1990). The reliability of estimates of migration in the peppered moth Biston betularia and some implications for selection-migration models. Biol J Linn Soc 39: 335-341.

Brakefield PM, Liebert TG (2000). Evolutionary dynamics of declining melanism in the peppered moth in the Netherlands. Proc R Soc Lond Ser B 267: 1953-1957.

Chapman JW, Nesbit RL, Burgin LE, Reynolds DR, Smith AD, Middleton DR et al. (2010). Flight orientation behaviors promote optimal migration trajectories in high-flying insects. Science 327: 682.

Chapman TA (1888). On melanism in Lepidoptera. Ent Mon Mag 25: 40.

Charlesworth B (1979). Evidence against Fisher's theory of dominance. Nat Lond 278: 848-849.

Clarke CA, Sheppard PM (1963). Frequencies of the melanic forms of the moth Biston betularia (L.) on Deeside and in adjacent areas. Nat Lond 198: 1279-1282.
Clarke CA, Sheppard PM (1966). A local survey of the distribution of industrial melanic forms in the moth Biston betularia and estimates of the selective values of these in an industrial environment. Proc $R$ Soc Lond Ser B 165: 424-439.

Clarke CA, Mani GS, Wynne G (1985). Evolution in reverse: clean air and the peppered moth. Biol J Linn Soc 26: 189-199.

Clarke CA, Clarke FMM, Dawkins HC (1990). Biston betularia (the peppered moth) in West Kirby, Wirral, 1959-1989: updating the decline of f. carbonaria. Biol J Linn Soc 29: 323-326.

Clarke CA, Grant B, Clarke FMM, Asami T (1994). A long term assessment of Biston betularia (L.) in one UK locality (Caldy Common near West Kirby, Wirral), 1959-1993, and glimpses elsewhere. Linnean 10: 18-26.

Cook LM (2003). The rise and fall of the carbonaria form of the peppered moth. Q Rev Biol 78: 399-417.

Cook LM, Mani GS (1980). A migration-selection model for the morph frequency variation in peppered moth over England and Wales. Biol J Linn Soc 13: 179-198.

Cook LM, Turner JRG (2008). Decline of melanism in two British moths: spatial, temporal and inter-specific variation. Heredity 101: 483-489.

Cook LM, Mani GS, Varley ME (1986). Postindustrial melanism in the peppered moth. Science 231: 611-613.

Cook LM, Rigby KD, Seaward MRD (1990). Melanic moths and changes in epiphytic vegetation in north-west England and north Wales. Biol J Linn Soc 39: 343-354.

Cook LM, Dennis RLH, Mani GS (1998). Melanic morph frequency in the peppered moth in the Manchester area. Proc $R$ Soc Lond Ser B 266: 293-297.

Cook LM, Riley AM, Woiwod IP (2002). Melanic frequencies in three species of moths in post industrial Britain. Biol J Linn Soc 75: 475-482.

Cook LM, Grant BS, Saccheri IJ, Mallet J (2012). Selective bird predation on the peppered moth: the last experiment of Michael Majerus. Biol Lett 8: 609-612.

Creed ER, Lees DR, Bulmer MG (1980). Pre-adult viability differences of melanic Biston betularia (L.) (Lepidoptera). Biol J Linn Soc 13: 251-262.

Daly D, Waltham K, Mulley J, Watts PC, Rosin A, Kemp SJ et al. (2004). Trinucleotide microsatellite loci for the peppered moth (Biston betularia). Mol Ecol Notes 4: 179-181.

Doncaster L (1906). Collective enquiry as to progressive melanism in Lepidoptera. Ent Rec 18: 165-168, 206-208, 222-276, 248-254.

Fisher RA (1928). The possible modification of the response of the wild type to recurrent mutations. Am Nat 62: 115-126.

Fisher RA (1930). The Genetical Theory of Natural Selection. Clarendon Press: Oxford.

Fisher RA (1931). The evolution of dominance. Biol Rev 6: 345-368.

Ford EB (1937). Problems of heredity in the Lepidoptera. Biol Rev 12: 461-503.

Ford EB (1953). The experimental study of evolution. Aust N Z Assoc Adv Sci 28 : $143-154$.

Ford EB (1955). Moths. Collins: London.

Ford EB (1964). Ecological Genetics, 4th edn. Chapman \& Hall: London, 1975.

Freitak D, Vanatoa A, Ots I, Rantala MJ (2005). Formation of melanin-based wing patterns is influenced by condition and immune challenge in Pieris brassicae. Ent Exp Appl 116: 237-243.

Grant BS (2004). Allelic melanism in American and British peppered moths. J Hered 95: 97-102.

Grant BS (2012). Industrial Melanism. Wiley: Chichester.

Grant BS, Wiseman LL (2002). Recent history of melanism in American peppered moths. J Hered 93: 86-90.

Grant BS, Owen DF, Clarke CA (1996). Parallel rise and fall of melanic peppered moths in America and Britain. J Hered 87: 351-357.

Grant BS, Cook AD, Clarke CA, Owen DF (1998). Geographic and temporal variation in the incidence of melanism in peppered moth populations in America and Britain. $J$ Hered 89: 465-471.

Haldane JBS (1924). A mathematical theory of natural and artificial selection. Trans Cambridge Philos Soc 23: 19-41.

Haldane JBS (1930). A note on Fisher's theory of the origin of dominance, and on a correlation between dominance and linkage. Am Nat 64: 87-90.

Haldane JBS (1956). The theory of selection for melanism in Lepidoptera. Proc $R$ Soc Lond Ser B 145: 303-306.

Howlett RJ, Majerus MEN (1987). The understanding of industrial melanism in the peppered moth (Biston betularia) (Lepidoptera: Geometridae). Biol J Linn Soc 30: $31-44$.

Jiang X-F, Luo L-Z, Lei Zhang L (2007). Relative fitness of near isogenic lines for melanic and typical forms of the Oriental Armyworm, Mythimna separata (Walker). Env Ent 36: 1296-1301.

Joron M, Frezal L, Jones RT, Chamberlain NL, Lee SF, Haag CR et al. (2011). Chromosomal rearrangements maintain a polymorphic supergene controlling butterfly mimicry. Nat Lond 477: 203-206.

Kettlewell HBD (1955). Selection experiments on industrial melanism in the Lepidoptera. Heredity 9: 323-342.

Kettlewell HBD (1956). A resume of investigations on the evolution of melanism in the Lepidoptera. Proc R Soc Lond Ser B 145: 297-303.

Kettlewell HBD (1958). A survey of the frequencies of Biston betularia (L.) (Lep.) and its melanic forms in Great Britain. Heredity 12: 51-72.

Kettlewell HBD (1961). Geographical melanism in the Lepidoptera of Shetland. Heredity 16: 393-402.

Kettlewell HBD (1973). The Evolution of Melanism. The Study of a Recurring Necessity. Clarendon Press: Oxford. 
Kettlewell HBD, Berry RJ (1961). The study of a cline. Amathes glareosa Esp. and its melanic F. edda Staud (Lep.) in Shetland. Heredity 16: 403-414.

Kettlewell HBD, Cadbury CJ (1963). Investigations on the origins of non-industrial melanism. Entom Rec 75: 149-160.

Kimura M (1983). The Neutral Theory of Molecular Evolution. Cambridge University Press New York.

Koch PB, Behnecke B, ffrench-Constant RH (2000). The molecular basis of melanism and mimicry in a swallowtail butterfly. Curr Biol 10: 591-594.

Lees DR (1981). Industrial melanism: genetic adaptation of animals to air pollution. In Bishop JA, Cook LM (eds.) Genetic Consequences of Man-Made Change. Academic Press: London, pp 129-176.

Lees DR, Creed ER (1975). Industrial melanism in Biston betularia: the role of selective predation. J Anim Ecol 44: 67-83.

Lees DR, Creed ER, Duckett JG (1973). Atmospheric pollution and industrial melanism. Heredity 30: 227-232.

Lewontin RC (1974). The Genetic Basis of Evolutionary Change. Columbia University Press: New York.

Liebert TG, Brakefield PM (1987). Behavioural studies on the peppered moth Biston betularia and a discussion of the role of pollution and lichens in industrial melanism. Biol J Linn Soc 31: 129-150.

Majerus MEN (1998). Melanism. Evolution in Action. Oxford University Press: Oxford.

Majerus MEN (2007). The Peppered Moth: The Proof of Darwinian Evolution, talk given at European Society for Evolutionary Biology, Uppsala, 2007. http://dx.doi.org/10.5061/ dryad.962262h9.

Majerus MEN, Brunton CFA, Stalker J (2000). A bird's eye view of the peppered moth. J Evol Biol 13: 155-159.

Mani GS (1980). A theoretical study of morph ratio clines with special reference to melanism in moths. Proc $R$ Soc Lond Ser B 210: 299-316.

Mani GS (1982). A theoretical analysis of the morph frequency variation in the peppered moth over England and Wales. Biol J Linn Soc 17: 259-267.

Mani GS (1990). Theoretical models of melanism in Biston betularia-a review. Biol J Linn Soc 39: 355-371.

Mani GS, Majerus MEN (1993). Peppered moth revisited: analysis of recent decreases in melanic frequency and predictions for the future. Biol J Linn Soc 48: 157-165.

Mayo OR, Bürger R (1997). The evolution of dominance: a theory whose time has passed? Biol Rev 72: 97-110.

Mikkola K (1979). Resting site selection by Oligia and Biston moths (Lepidoptera: Noctuidae and geometridae). Ann Ent Fenn 45: 81-87.

Mikkola K (1984). On the selective forces acting in the industrial melanism of Biston and Oligia moths (Lepidoptera: Geometridae and Noctuidae). Biol J Linn Soc 21: 409-421.

Mikkola K, Rantala MJ (2010). Immune defence, a possible non-visual selective facto behind the industrial melanism of moths (Lepidoptera). Biol J Linn Soc 99: 831-838.

Murray DD, Bishop JA, McNair MR (1980). Melanism and predation in the moths Biston betularia and Phigalia pilosaria. Proc $R$ Soc Lond Ser B 210: 277-283.

Owen DF (1997). Natural selection and evolution in moths: homage to JW Tutt. Oikos 78 $177-181$

Papa R, Morrison CM, Walters JR, Counterman BA, Chen R, Halder G et al. (2008). Highly conserved gene order and numerous novel repetitive elements in genomic regions inked to wing pattern variation in Heliconius butterflies. BMC Genom 9: 345-360.

Porritt GT (1907). Melanism in Yorkshire Lepidoptera. Rep Br Ass Adv Sci 1906 316-325

Prest W (1877). On melanism and variation in Lepidoptera. Entomologist 10: 129-131.
Punnett RC (1915). Mimicry in Butterflies. Cambridge University Press: Cambridge. Rudge DW (2006). H.B.D. Kettlewell's research 1937-1953: the influence of E.B. Ford, E.A. Cockayne and P.M. Sheppard. Hist Philos Life Sci 28: 359-388.

Rudge DW (2009). H. B. D. Kettlewell's Research, 1934-1961. The Influence of J. W. Heslop Harrison. In: Cain J, Ruse M (eds.) Descended from Darwin. Insights into the History of Evolutionary Studies, 1900-1970. American Philosophical Society: Philadelphia, pp 234-270.

Rudge DW (2010). Tut-tut Tutt, not so fast. Did Kettlewell really test Tutt's explanation of industrial melanism? Hist Philos Life Sci 32: 493-520.

Saccheri IJ, Rousset F, Watts PC, Brakefield PM, Cook LM (2008). Selection and gene flow on a diminishing cline of melanic peppered moths. Proc Natl Acad Sci USA 105 $16212-16217$.

Sheppard PM (1959). The evolution of mimicry; a problem in ecology and genetics. Cold Spring Harb Symp Quant Biol 24: 131-140.

Steward RC (1977a). Melanism and selective predation in three species of moths. J Anim Ecol 46: 483-496.

Steward RC (1977b). Industrial and non-industrial melanism in the peppered moth Biston betularia (L.). Ecol Ent 2: 231-243.

Stoehr AM (2006). Costly melanin ornaments: the importance of taxon? Funct Ecol 20 276-281.

Talloen W, Van Dyck H, Lens L (2004). The cost of melanization: butterfly wing coloration under environmental stress. Evolution 58: 360-366.

True JR (2003). Insect melanism: the molecules matter. Trends Ecol Evol 18 640-647

Tutt JW (1891). Melanism and melanochroism in British Lepidoptera. Ent Rec 1: 5-7.

Tutt JW (1894). Woodside, Burnside, Hillside and Marsh Swan. Sonnenschein: London. Tutt JW (1896). British Moths. Routledge: London.

van Ooik T, Pausio S, Rantala MJ (2008). Direct effects of heavy metal pollution on the immune function of a geometrid moth. Chemosphere 71: 1840-1844.

Van't Hof AE, Saccheri IJ (2010). Industrial melanism in the peppered moth is not associated with genetic variation in canonical melanisation gene candidates. PLoS One 5: e10889.

Van't Hof AE, Edmonds N, Dalíková M, Marec F, Saccheri IJ (2011). Industrial melanism in British peppered moths has a singular and recent mutational origin. Science $\mathbf{3 3 2}$ 958-960.

Van't Hof AE, Nguyen P, Dalíková M, Edmonds N, Marec F, Saccheri IJ (2013). Linkage map of the peppered moth, Biston betularia (Lepidoptera, Geometridae): a model of industrial melanism. Heredity 110: 283-295.

White FB (1877). Melanochroism, etc., in Lepidoptera. Entomologist 10: 126-129.

Whittle PDJ, Clarke CA, Sheppard PM, Bishop JA (1976). Further studies on the industrial melanic moth Biston betularia (L.) in the northwest of the British Isles. Proc $R$ Soc Lond Ser B 194: 467-480.

Windig JJ (1999). Trade-offs between melanization, development time and adult size in Inachis io and Araschnia levana (Lepidoptera: Nymphalidae)? Heredity $\mathbf{8 2}$ $57-68$

Wittkopp PJ, Carroll SB, Kopp A (2003). Evolution in black and white: genetic control of pigment patterns in Drosophila. Trends Genet 19: 495-504.

Wood CR, Reynolds DR, Wells PM, Barlow JF, Woiwod IP, Chapman JW (2009). Flight periodicity and the vertical distribution of high-altitude moth migration over southern Britain. Bull Ent Res 99: 525-535.

Wright S (1929). Fisher's theory of dominance. Am Nat 63: 274-279. 